\title{
Life-LCA: the first case study of the life cycle impacts of a human being
}

\author{
David Bossek $^{1}{ }^{10} \cdot$ Marcel Goermer $^{1} \cdot$ Vanessa Bach $^{1} \cdot$ Annekatrin Lehmann $^{1} \cdot$ Matthias Finkbeiner $^{1}$
}

Received: 25 November 2020 / Accepted: 6 May 2021 / Published online: 8 June 2021

(c) The Author(s) 2021, corrected publication 2021

\begin{abstract}
Purpose Besides politics and the private sector, changes in the consumption pattern of individuals can significantly contribute to sustainable development. The recently published Life-LCA method adapts life cycle assessment to analyse human beings and quantifies their impacts. This method is applied for the first time in this case study to provide insights and remaining challenges.

Methods The environmental impacts caused by the life cycle of a middle-aged German man ("Dirk") were determined by the Life-LCA method from his birth until his current age (0-49 years). To determine and quantify reduction options, a current 1-year period was analysed in detail by a baseline scenario of his current consumption and an optimized scenario after changing his consumption patterns. The environmental impact assessment included global warming (GWP), acidification (AP), eutrophication (EP), and photochemical ozone creation potentials (POCP).

Results and discussion Dirk has emitted 1,140 t CO 2 -eq., $4.48 \mathrm{t} \mathrm{SO}_{2}$-eq., $1.69 \mathrm{t} \mathrm{PO}_{4}$-eq., and $0.537 \mathrm{t}_{2} \mathrm{H}_{4}$-eq. emissions over his current lifetime. Transportation dominated all considered impact categories (40 up to 55\%). Energy and water consumption is the second most significant product category for GWP (39\%). Food products, with 10\%, are the third biggest contributor to GWP, but contribute rather significantly to the impact categories AP (34\%), EP (42\%), and POCP (20\%). The optimized scenario analysis revealed significant reductions for all studied impacts in the range of $60-65 \% . \mathrm{CO}_{2}$-eq. emissions were reduced from 28 to 10 t/a. The remaining challenges include data collection for childhood, gaps and inconsistencies of existing data for consumer goods, the allocation between product users, and depreciation of long-living products.

Conclusion The first Life-LCA case study confirmed the applicability of the Life-LCA method. It showed that the Life-LCA approach allows for tracking individual consumption patterns of a human being. The impacts of behavioural changes were quantified, and significant reduction potentials of the environmental impacts were revealed. Additional case studies on people of different age, region, culture, and lifestyle are needed for further insights and methodological refinements.
\end{abstract}

Keywords Life cycle assessment (LCA) · Environmental awareness $\cdot$ Sustainable consumption $\cdot$ Personal environmental footprint $\cdot$ Life-LCA $\cdot$ Sustainable lifestyles

\section{Introduction}

Promoting sustainable consumption and production is one of the 17 Global Sustainable Development Goals. In addition to politics and the private sector, consumers are also addressed, as changes in a human being's lifestyle can significantly contribute to sustainable development (United Nations

Communicated by Marzia Traverso.

David Bossek

david.bossek@tu-berlin.de

1 Institute of Environmental Technology, Chair of Sustainable Engineering, Technische Universität Berlin, Strasse des 17. Juni 135, 10623 Berlin, Germany
2016). Private consumption accounts for approximately $72 \%$ of global $\mathrm{CO}_{2}$-eq. emissions, with around $50 \%$ of these emissions being caused by the richest $10 \%$ of the world population (Hertwich and Peters 2009; Gore et al. 2020).

Although noteworthy improvements in environmental product design have been achieved over the past decades, these relative improvements appear to be outpaced by a growing consumption pattern due to rising living standards (Glatzer et al. 2015; Steinemann et al. 2017). Thus, lifestyle changes and consumption patterns play a substantial role in mitigating global emissions (Princen 2001; Alfredsson 2004; Schanes et al. 2016). According to Berg et al. (2018), awareness of a more conscious use of natural resources is present in society, but significant behavioural changes in 
consumption can barely be observed (Notter et al. 2013; Ortega-Egea et al. 2014).

The life cycle assessment (LCA) approach allows for the analysis of a variety of environmental impacts along the entire life cycle of products (ISO 2006). Initially developed for product assessment, the LCA approach has been adapted to organizations (ISO 2014; Martínez-Blanco et al. 2016) and more recently to account for the environmental impacts of human beings over their whole life. This approach is called Life-LCA and was published by Goermer et al. (2019).

The Life-LCA method improves consistency, specificity, and comprehensiveness of assessing human being's environmental impacts in the field of LCA. Further, quantifying the individually caused environmental damage might be a solution for significant changes in consumer behavior as motivation is higher when environmental impacts become tangible and improvement can be tracked.

Goermer et al. (2019) provided the methodological framework of Life-LCA and described differences to other LCA applications. Fundamental and operational challenges were addressed, such as the consideration of human development and changing consumption behaviours over time, determination and delimitation of potential Life-LCA applications, and the difficulty of the assessment due to the complex and diverse consumption patterns of a human being (e.g., collection of complex and diverse consumption data).

So far, no Life-LCA case studies have been published, and this paper fills this research gap. Thus, this paper aims to apply the Life-LCA method for the first time in a real-life case study to confirm its applicability and verify whether it provides meaningful results.

The human being chosen as study object is a German male (Dirk Gratzel, in the following, simply addressed as "Dirk"). The use of the study object's name and further associated personal information in this study ensued under the full agreement of Dirk. He is currently 50 years old, married, and lives in a house in a German village near the city of Aachen, together with his wife and one of his five children. Dirk is CEO of a medium-sized company, and his leisure activities are dominated by hunting and sports. He is neither a representative of a European or German citizen nor human beings in general. For a first Life-LCA case study, representativeness in selecting the study object was not intended or feasible. Dirk was selected because he volunteered to take the significant burden in data collection as he wanted to know and then improve his environmental impacts. It is part of his mission to die with no harmful impacts on the environment, which has received quite some interest in popular media around the world (Der Spiegel 2018; The Hindu 2018; The New York Times 2018).

In this study, results are presented in two ways. First, the environmental impacts of Dirk are analysed from birth-tocurrent life year over the impact categories Global Warming
Potential (GWP), Acidification Potential (AP), Eutrophication Potential (EP), and Photochemical Ozone Creation Potential (POCP). This analysis represents the actual LifeLCA result view (from cradle-to-current life year). Further, for detailed analysis and to determine the relevance of Dirk's change in lifestyle, results are provided in a second step for two recent consecutive years (performance tracking from baseline year to the following year with significant optimizations of his current consumption patterns).

In the following chapters, the materials and methods (see Sect. 2) used in this study, followed by the study results (see Sect. 3), a discussion of the challenges (see Sect. 4), and finally, a conclusion and outlook (see Sect. 5) are presented.

\section{Materials and methods}

This chapter outlines the goal and scope of the study, system boundaries and allocation (see Sect. 2.2), the life cycle inventory (see Sect. 2.3), and impact assessment method (see Sect. 2.4).

\subsection{Goal and scope}

This study aims to quantify the environmental impacts over the life of the human being "Dirk" by applying the Life-LCA approach (Goermer et al. 2019). As the key applications of Life-LCA are individual performance tracking and life optimization, the term reporting unit is used for this individual Life-LCA, which was previously introduced for the O-LCA method (UNEP/SETAC 2015). Thus, the reporting unit is set to the life of Dirk (current life span: 0-49 years) and the range of his consumed products (reporting flow). A further goal was the analysis of Dirk's consumption impacts over a current 1-year period (baseline scenario before his consumption patterns changed) (see Sect. 3.2) compared to an optimized scenario after changing his consumption behaviour (see Sect. 3.3). For the optimized scenario, improvement measures for reducing environmental impacts of certain consumption behaviors, as recommended by two German environmental NGOs, were assessed. Further, the results are evaluated for their plausibility by comparing them with results calculated by the German Environmental Agency's (UBA) carbon calculator (see Sect. 4.3).

\subsection{System boundaries and allocation}

Life-LCAs have two-dimensional assessments, where system boundaries are defined for both dimensions - the higher-level human life cycle (dimension 1) and the lowerlevel product life cycle (dimension 2) (Goermer et al. 2019). For determining the environmental impacts of Dirk's life, the temporal system boundaries for dimension 
1 were set to his current life span, i.e., from his birth until his $49^{\text {th }}$ birthday. In the absence of detailed data, the "childhood and youth stage" (0-17 years) was considered by assuming that in those first life years, the consumption was just half (50\%) of the consumption in the baseline year for all product categories excluding "transport" (see Sect. 2.3.2 for a list of product categories). Transport was excluded as a large share of the baseline year's impacts was due to work-related travels. As Dirk obtained his driver's license (18 years old), all means of transport were considered. This simplified approach for the "childhood and youth stage" was applied due to a missing methodology and specific consumption data. However, for some product categories, more specific past acquis data and assumptions on past consumption behaviour were considered (for details, see Sect. 2.3.1).

As a second scope of the analysis, the system boundaries for dimension 1 were set to a 1 -year period to compare different consumption patterns (baseline and optimized scenario). Data collection was carried out during a 2-month period in the years 2017 (baseline scenario) and 2018 (optimized scenario), respectively. Consumed products (e.g., food, cosmetic products, energy use at home) were documented and extrapolated to the full calendar year with a relative correction of any seasonal effects (e.g., increased heat consumption in winter) (see Sect. 3.1). The system boundaries of dimension 2 (the product life cycle) were set to include all consumed products and services. In both cases, the environmental impacts of the consumed products were covered from cradle-to-grave; i.e., impacts of all life cycle stages (production of raw materials, product production, use, end-of-life) were considered.

The inclusion or allocation of products consumed by his children that are potentially influenced by Dirk's decisions (e.g., in early life years, parents choose food and clothes for their children) were excluded for consistency reasons. Otherwise, Dirk's childhood impacts would have to be allocated to his parents as well. Another allocation option would be to allocate the burden of each child partly to Dirk. Therefore, the exact moment of free will and ability to decide would have to be evaluated for each of Dirk's children. Due to a missing methodology and the complexity of this question, this allocation option was not applied. It is suggested to carry out different childhood allocation options in future studies to close this methodological gap (see Sect. 4.2: Allocation of the childhood phase and other socio-psychological interactions between human beings). Further exclusions were financial investments beyond physical goods (e.g., investments in stocks) and goods received as an inheritance (e.g., properties and houses), which might have a significant impact and should be considered in future studies, if applicable and meaningful. For allocation, the co-product allocation rules apply. As for end-of-life-allocation, the avoided burden approach (0:100) was applied; i.e., credits were given for recycling, while secondary materials carried the burden of primary material production. Recycling credits were modelled based on current German recycling quotas for the different materials (Statistisches Bundesamt 2017).

For Life-LCA, some additional allocation rules need to be specified. For products shared with other persons, Dirk documented the product use ratio (see Sect. 2.3.1). For instance, amounts of food (e.g., shared dishes) and drinks (e.g., a shared bottle of wine or water) served at restaurants were estimated this way. The shared use of the same products (e.g., housing or electronics products) was allocated according to the product sharing ratio. Two additional family members are living in Dirk's household. Thus, the environmental impacts of a device (e.g., television) allocated to Dirk were assumed to be one-third. The effective usage of a shared product from each household member was not considered. It would have been associated with high efforts for data collection and the other family members' willingness to play a substantial role in monitoring their behaviour, which was not a feasible option for this study.

\subsection{Life-cycle inventory}

This chapter explains the method for data collection and calculation (see Sect. 2.3.1) and the subsequent establishment of product clusters (see Sect. 2.3.2).

\subsubsection{Data collection and calculation}

To calculate Dirk's Life-LCA, a relatively comprehensive and time-demanding data collection had to be performed to cover all consumed products. Therefore, data collection was performed with tailor-made sets of data collection sheets (available at: https://www.see.tu-berlin.de/menue/research/ data_tools/life_lca_life_cycle_impacts_of_a_human_being/ parameter/en/). The different sheets cover continuously (e.g., food, toilet paper), discontinuously consumed products (e.g., clothing), and acquis data (e.g., desk, television). Acquis data refers to all consumed products with an average life span of a year or more and cannot be covered within a short (weeks, months) monitoring period. Digital drop-down tables were created in Excel ${ }^{\circledR}$, where consumed products were documented according to pre-defined product categories (e.g.,"food" or "energy and water") and clusters (e.g., non-alcoholic beverages in the product category "food"), sub-clusters (e.g., juice), and types (e.g., orange juice) to simplify the subsequent data analysis and establishment of clusters (see Sect. 2.3.2 for a detailed explanation of the product cluster). The product categories were chosen in accordance and close cooperation with Dirk to cover all necessary products and facilitate his data collection through a clear structure. Where relevant, Dirk documented more 
specific information to characterize the product, e.g., if the product was bought second-hand (e.g., for clothing) or of which material the product is made of (e.g., fleece or cotton).

Following aspects were applied for data collection:

(i) Continuously consumed products (e.g., meat): data collection on the consumed amount, number of persons consuming it, additional specific information (e.g., in the case of dear "own shot game"), the geographical origin (limited to "Germany," "Europe," and "worldwide"), and primary packaging of the consumed product (e.g., plastic bottle for orange juice) as well as classification into disposable and reusable.

(ii) Discontinuously consumed products (e.g., clothes): additional information, such as average life span or used material of products.

(iii) Acquis data (e.g., desk, television): additional information such as the average life span or user ratio of the products.

To collect data for Dirk's consumption in the past, data of previous years for the categories transport, energy, water, food, and pets were collected as detailed as he could remember. Past acquis data were derived based on his memories or records (e.g., invoices, logbooks). Dirk's mobility behaviour (e.g., vehicle type, $\mathrm{km}$ driven per vehicle, fuel type) could be documented rather precisely from the age of 18 on, covering nine cars and several motorcycles. Until he started hunting in 2015 , all meat consumed was assumed to be from industrial production. His pets (a hunting dog and a cat), including accessories (e.g., bucket, leash) and feed, were taking into account from 2004 onwards. The pets are fully allocated (conservative approach) to Dirk, who constantly cared for the pets in all years. For future individual Life-LCAs, the allocation of the pet's environmental impacts have to be chosen according to the respective circumstances of the study objects' living situation.

His past living conditions in several apartments and with different energy supplies were also included. For example, he has only been using electricity and gas from renewable sources since 2014. In contrast, before 2014, he used an average electricity consumption mix and oil as a thermal energy source.

For some products, the seasonal variation during the monitoring periods in 2017 and 2018 had to be considered. For example, thermal energy consumption was recorded over the 2 months of February and March; thus, a distorted extrapolation to 1 year would overestimate the yearly consumption. Therefore, correction factors based on the average monthly thermal energy consumptions considering German national statistics (Gasverbrauchsrechner 2019) were applied. Based on these numbers, thermal energy consum- ption in the months February and March accounts for 25.5\% of the yearly consumption. Another possibility to account for yearly energy and electricity consumption could be to refer to past gas/electricity bills for missing months (if available). The methodology with the correction factor can be favoured: (a) if someone just moved into an apartment/house and there are no past records available, (b) the study object changed to more efficient energy systems and past records would not be adequate anymore, and (c) the system boundaries are set to specific months. Furthermore, as it was not possible to measure the specific energy and water consumption of hotel stays, average data were used. The energy consumption per hotel stay was estimated at $25 \mathrm{kWh}$ of total energy consumption (thermal and electric) (Beccali et al. 2009; Filimonau et al. 2011). A conservative approach was chosen to account for energy and water consumption during a working day (time not spent at home-no water and electricity meters available) by assuming $40 \mathrm{~h}$ of work per week considering 168 total hours available. Thus, time spent at work was calculated at $23.8 \%$ - hours spent at his workplace per week, divided by the total hours available per week - and rounded up to $25 \%$. The water and energy consumption measured at home was assumed to be the basis during working hours, assuming a similar consumption behaviour like at home. Therefore, an additional $25 \%$ of measured energy and water consumption at home was modelled as consumption at work. It was also assumed that the German electricity mix for energy was used for work and in hotels.

After completing the comprehensive primary data collection described above, the different used products, services, and resources need to be connected with the respective background data. Due to the breadth and sheer number of products needed, different background data sources had to be used. While it is understood that this mix of data sources introduces inconsistencies in the overall result, it is the only option available to date to cover the broad set of products consumed in Dirk's life applying the LCA method.

The following data sources were used to model the consumed products (see Fig. 1): (1) common LCA databases, which are GaBi database (Thinkstep 2018), Ecoinvent 3.3 (Wernet et al. 2016), and Agribalyse database 1.3 (Koch and Salou 2014); (2) Environmental Product Declarations (EPD) based on Product Category Rules (PCR); (3) documents published by the Product Environmental Footprint (PEF) initiative (European Commission 2019); and (4) additional LCA reports and case studies (later addressed as proxy (own model) and reference materials). The particular order of the hierarchy highlights the decreasing quality of the underlying data, as shown in Fig. 1. The practice has shown that EPD was ultimately not used (see Fig. 2). Nonetheless, the hierarchy should be applied in this order as EDP is the more established database compared to PEF (European Commission 2018; Minkov et al. 2020). 
Fig. 1 Hierarchy of the used datasets for modelling

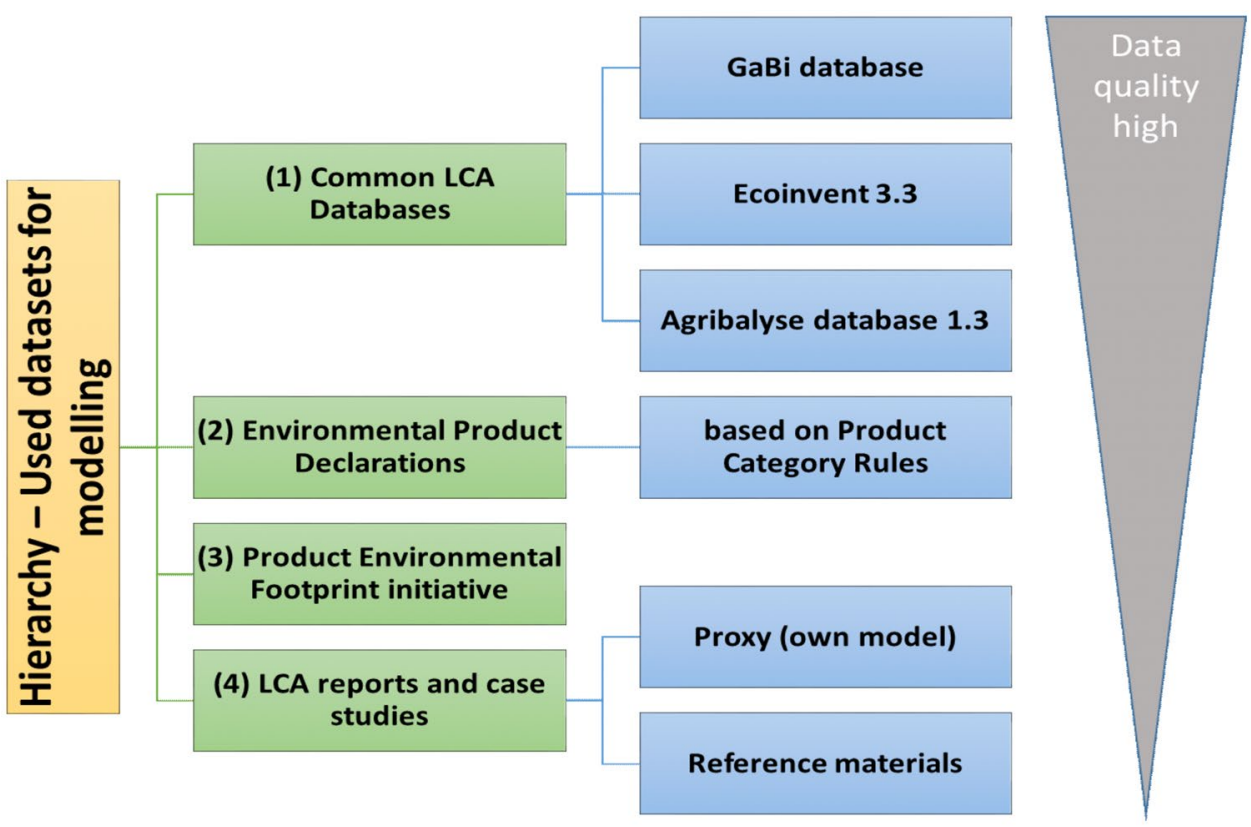

In cases where more than one dataset for the same product was available, data were chosen according to the hierarchy presented in Fig. 1 (e.g., when data for apples are available in $\mathrm{GaBi}$ and a published case study, $\mathrm{GaBi}$ data were chosen).

Moreover, in the case of different options from common LCA databases, Gabi database was preferred over Ecoinvent and Agribalyse, due to having the most state-of-the-art and up-to-date datasets available. The LCI and LCIA were modelled with GaBi software service pack 39 (Thinkstep 2018). Proxy (own model) means that the product itself was modelled based on its bill of material (e.g., soft furniture such as a sofa: no dataset at product level was available). Thus, it is modelled based on a publication in which typical material compositions of average soft furniture are listed (DHP furniture 2019). The term "reference materials" (e.g., $\mathrm{GaBi}$ or Ecoinvent reference material) was used when there was neither information about the average composition nor aggregated product datasets or specific case studies available. If such a product consisted mainly of one material, it was modelled based on an average material dataset available (e.g., Dirk has two wooden tables for which no data was
Fig. 2 Relative share of data sources used for modelling the different product categories

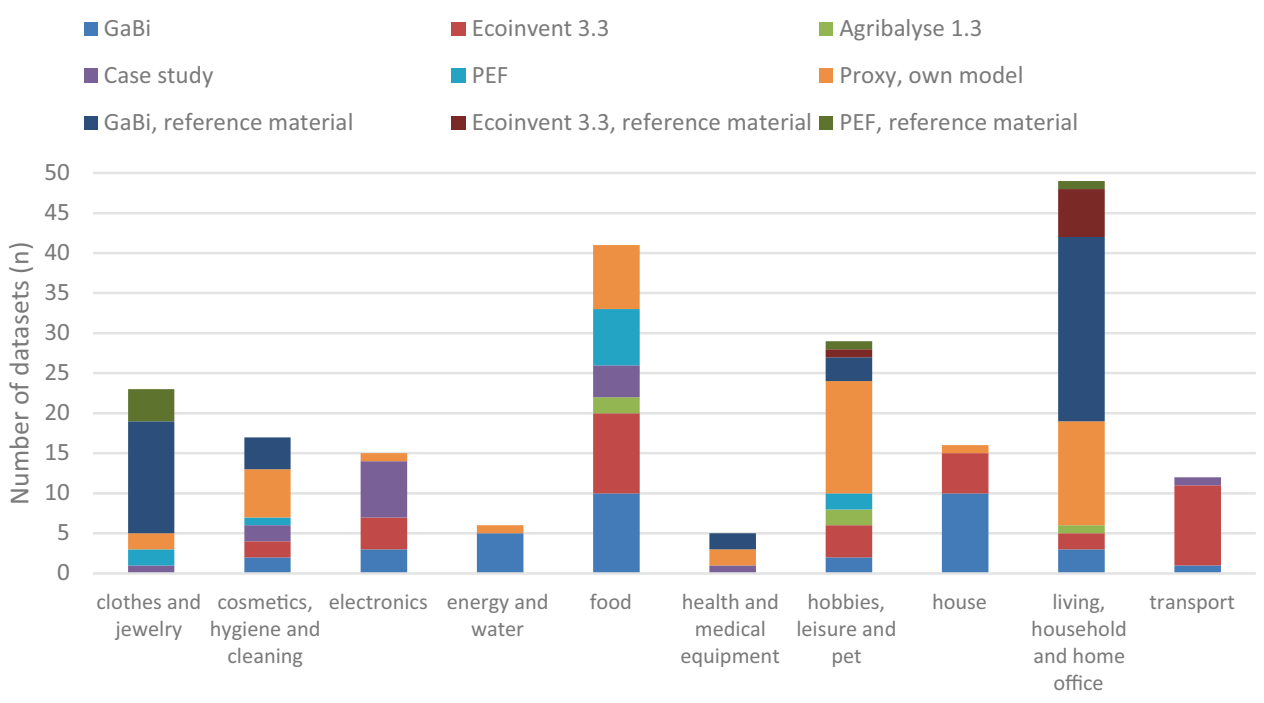

Product categories 
available; thus, the table was only modelled with an average dataset for wood mix in Germany. Such a simplification neglected non-wooden parts like screws.

\subsubsection{Modelling of product clusters}

Dirk recorded a broad variety of products during the data collection and monitoring phase, based on predefined product categories (see Sect. 2.3.1). Not all of these products could be modelled in detail due to limited data availability. Thus, a bottom-up product clustering scheme was applied according to Goermer et al. (2019), which is based on a concept to establish product clusters according to data availability. Products with missing LCA data were assigned to similar products with available LCA datasets (e.g., buns, pastry, and bread are clustered as "bakery products" and modelled with the dataset for bread).

Overall, 10 product categories cover 213 product clusters (e.g., the product category "food" covers the cluster tropical fruits, which refers to oranges, kiwis, and pineapples among others). $N$ refers to the number of considered product clusters (e.g., "Bakery products" equals one product cluster out of 41 in the product category "food" $(N=41))$. The following product categories were determined:

- "clothes and jewellery" $(N=23)$,

- "cosmetics, hygiene, and cleaning" $(N=17)$,

- "electronics" $(N=15)$,

- "energy and water" $(N=6)$,

- "food" $(N=41)$,

- "health and medical equipment" $(N=5)$,

- "hobbies, leisure, and pet" $(N=29)$,

- "house" $(N=16)$,

- "living, household, and home office" ( $N=49)$,

- "transport" $(N=12)$.

The highest number of product clusters were established for the product categories "living, households, and home office" (covering 49 clusters) and "food" (covering 41 clusters), whereas "health and medical equipment" just covered 5 clusters. Reasons for fewer clusters were either a limited number of products in general (e.g., "energy and water") or the fact that Dirk consumed only few of the products covered by the product category (e.g., only contact lenses or painkillers in the product category "health and medical equipment"). All product clusters are documented in detail in the supplementary material SM1 (see SM1: 3. Clusters and data sets).

Figure 2 summarizes the different data sources used for modelling and different product clusters (datasets) of the 10 product categories for this specific case study. Some categories (e.g., the product categories "energy and water," "house," and "transport") are mainly modelled using existing databases; i.e., aggregated datasets were available. In contrast, other product categories (e.g., "clothes and jewellery") are mainly modelled based on reference materials (see Sect. 2.3.1 for an explanation of the term), case studies, and proxies. The differentiation between "GaBi" and "Gabi reference materials" (same applies for Ecoinvent and PEF) was made for transparency reasons and to indicate that current LCA databases lack datasets, especially for these product categories.

Data availability in LCA databases and case studies differs per product category. For "transport, "housing and energy," and "water" as well as for "food" and "electronic products," a fair amount of data on product level is available ( $>75 \%$ of the clusters were modelled by using aggregated product-based datasets from databases, case studies, or PEF).

\subsection{Impact assessment}

The life cycle impact assessment (LCIA) phase included the calculation of the Global Warming Potential (GWP), Acidification Potential (AP), Eutrophication Potential (EP), and Photochemical Ozone Creation Potential (POCP). The impact assessment method CML-IA (version 2016) (Guinée et al. 2001; van Oers et al. 2002; CML-Department of Industrial Ecology 2016) was applied for all impact categories. CML-IA was chosen as it is one of the most commonly applied approaches for assessing environmental impacts in LCA (Bach and Finkbeiner 2017). Additionally, most of the reviewed case studies, which served as data sources for modelling the different impact categories, used CML-IA. Therefore, the effort of results conversion was reduced.

However, when different impact assessment methods were applied for some products, case study results had to be converted into CML-IA results. This conversion was done by a re-calculation via the characterization factors of the corresponding reference substances. For example, the results of the impact category acidification applying the characterization model of Seppälä et al. (2006) (accumulated exceedance expressed in [molc $\mathrm{H}+$ eq.]) had to be translated to results of the model developed by Hauschild and Wenzel (1998) used in CML-IA (expressed in [ $\mathrm{kg} \mathrm{SO}_{2}$-eq.]). Therefore, the amount of $\mathrm{SO}_{2}$-eq. was determined by dividing the LCIA result based on the model of Seppälä et al. (2006) through the respective characterization factor for this substance; i.e., $1.31 \mathrm{~mol}$ of $\mathrm{H}+$-eq. is translated into $1 \mathrm{~kg} \mathrm{SO}_{2}$ emission into air. Again, this procedure implies obvious simplifications and inconsistencies. However, it was inevitable to cover the broad set of products consumed by Dirk as no consistent data is available. 


\section{Results}

This chapter presents the results of Dirk's Life-LCA (see Sect. 3.1), the baseline scenario (Sect. 3.2), and the optimized scenario (see Sect. 3.3).

\subsection{Life-LCA}

Figure 3 shows Dirk's Life-LCA results (age 0-49) for the four considered impact categories. Dirk's life caused significant environmental impacts as a GWP of 1,140 $\mathrm{tCO}_{2}$-eq., an $\mathrm{AP}$ of $4.48 \mathrm{t} \mathrm{SO}_{2}$-eq., an $\mathrm{EP}$ of $1.69 \mathrm{t} \mathrm{PO}_{4}$-eq., and a POCP of $0.537 \mathrm{t} \mathrm{C}_{2} \mathrm{H}_{4}$-eq. show.

Dirk's traffic behaviour (in total nine cars over 30 years), as well as business flights, resulted in predominant shares of the product category "transport" for GWP (42\%), AP (40\%), and POCP (54\%) (see Fig. 3). Further, "transport" is the second largest contributor to EP with a share of $38 \%$. Food products have the highest share for EP (42\%). In this product category, especially dairy products cause high impacts in all impact categories. Further contributors are industrial meat (GWP, AP, EP), coffee (GWP, POCP, AP), bakery products (EP), and marine fish (POCP). "Food" contributes to GWP with a share of $11 \%$ to AP (34\%) and POCP (20\%). Dirk used oil as an energy supply for heating and conventional electricity from 1986 until 2014, which resulted in high shares (39\%) of the product category "energy and water" for GWP, whereas the shares for EP, AP, and POCP are relatively low, in between 6 and 12\%. Pets and mainly his current dog are responsible for more than half of the impacts in the product category "hobbies, leisure, and pets." Total shares of GWP, EP, and AP are between 3 and 7\%; however, for POCP "hobbies, leisure, and pets" is the third-largest contributor with $11 \%$. Other product categories, such as "electronics" or "clothes and jewellery," have a minor significance for the results $(0-5 \%)$. When dividing his Life-LCA GWP results through the investigated years, Dirk has an average yearly impact of around $23.3 \mathrm{t} \mathrm{CO}_{2}$-eq., which is more than twice the average German (UBA 2019). If Dirk would not consider any lifestyle improvements (environmentally speaking) in the future and under the crude assumption of a continued constant average impact of $23.3 \mathrm{t} \mathrm{CO}_{2}$-eq. per year until his statistically expected death (78.5 years), he would emit around 1,830 t CO 2 -eq. until his end of life (Statista 2019). In 2019, total greenhouse gas emissions reached 810 million tons of $\mathrm{CO}_{2}$-eq. in Germany. The government aims to achieve climate neutrality by 2050 . Without enormous

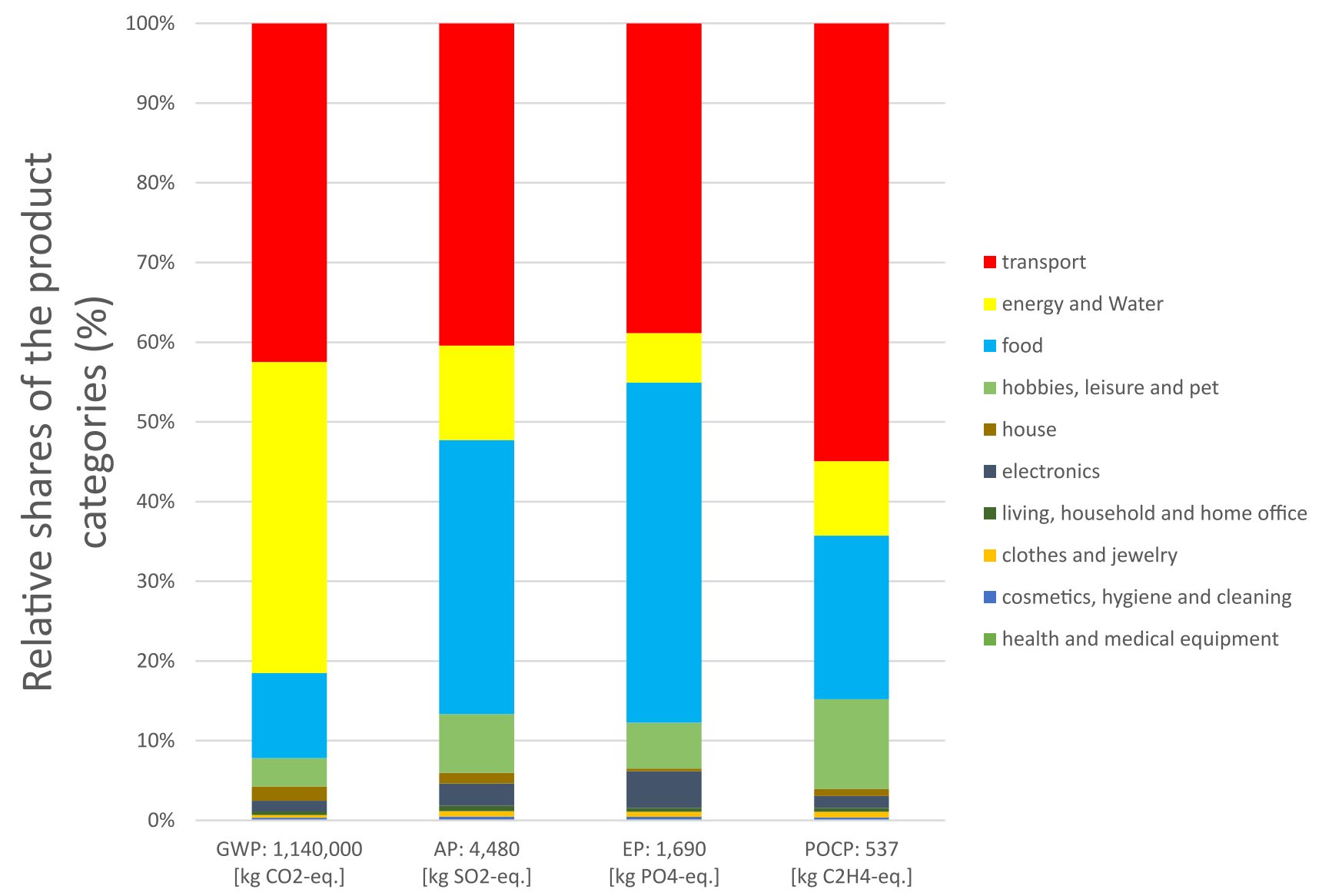

Fig. 3 Life-LCA results and relative shares of product categories 
and fast efforts of private persons and industry, the set targets will not be achieved (UBA 2021).

In addition to the LCA results over his life to date, a more detailed analysis of Dirk's $48^{\text {th }}$ year and the associated impacts are presented in the next chapter.

\subsection{Baseline scenario}

The baseline scenario provides results for one year of Dirk's current life (his $48^{\text {th }}$ life-year, which is included in the LifeLCA presented in Sect. 3.1). His $48^{\text {th }}$ life year has a relative share of around $2.5 \%$ regarding the Life-LCA presented in the previous section. If Dirk consumed yearly as much as in his $48^{\text {th }}$ year, he would have reached the Life-LCA results presented in Fig. 3 earlier, around his $40^{\text {th }}$ birthday. However, since his first years in the "childhood and youth stage" were only counted half, he emitted the emissions presented in Sect. 3.1 on his $49^{\text {th }}$ birthday.

Figure 4 shows that the product category "transport" causes the highest shares of impacts for all studied impact categories (with a contribution from a minimum of $45 \%$ (AP) up to a maximum of $65 \%$ (GWP)). In the baseline scenario, Dirk used a large SUV (40,500 km per year), travelled by air (18,600 km per year), and high-speed trains
(11,500 km per year) for business trips (see Table 2 for an extract of his consumption inventory). His long-distance high-speed train rides (ICE/EC-trains) (still 16\% of all travelled kilometres) result in an impact on the overall $\mathrm{CO}_{2}$-eq. emissions of around 1\% regarding the total GWP impacts for this product category, due to a high user-ratio and the use of renewable electric power in Germany (Deutsche Bahn 2019).

When compared with the relative shares presented in Fig. 3 (Life-LCA results), the share of "energy and water" in the baseline scenario decreased by around $50 \%$ for GWP and doubled for AP and EP due to the use of oil as an energy carrier for heating and conventional electricity from 1986 until 2014. Nevertheless, "energy and water" is still the second largest contributor for the impact categories GWP (15\%) and AP (26\%) in the baseline scenario. Further, energy consumption (which was modelled with an average electricity mix) from overnight stays in hotels (40 per year) and his workplace in Aachen are contributing significantly (50\%) to this product category.

The product category "food" is the second dominant product category for EP (27\%) and POCP (17\%) due to Dirk's consumption of dairy products and meat (see Table 1). Compared to the relative shares of the overall

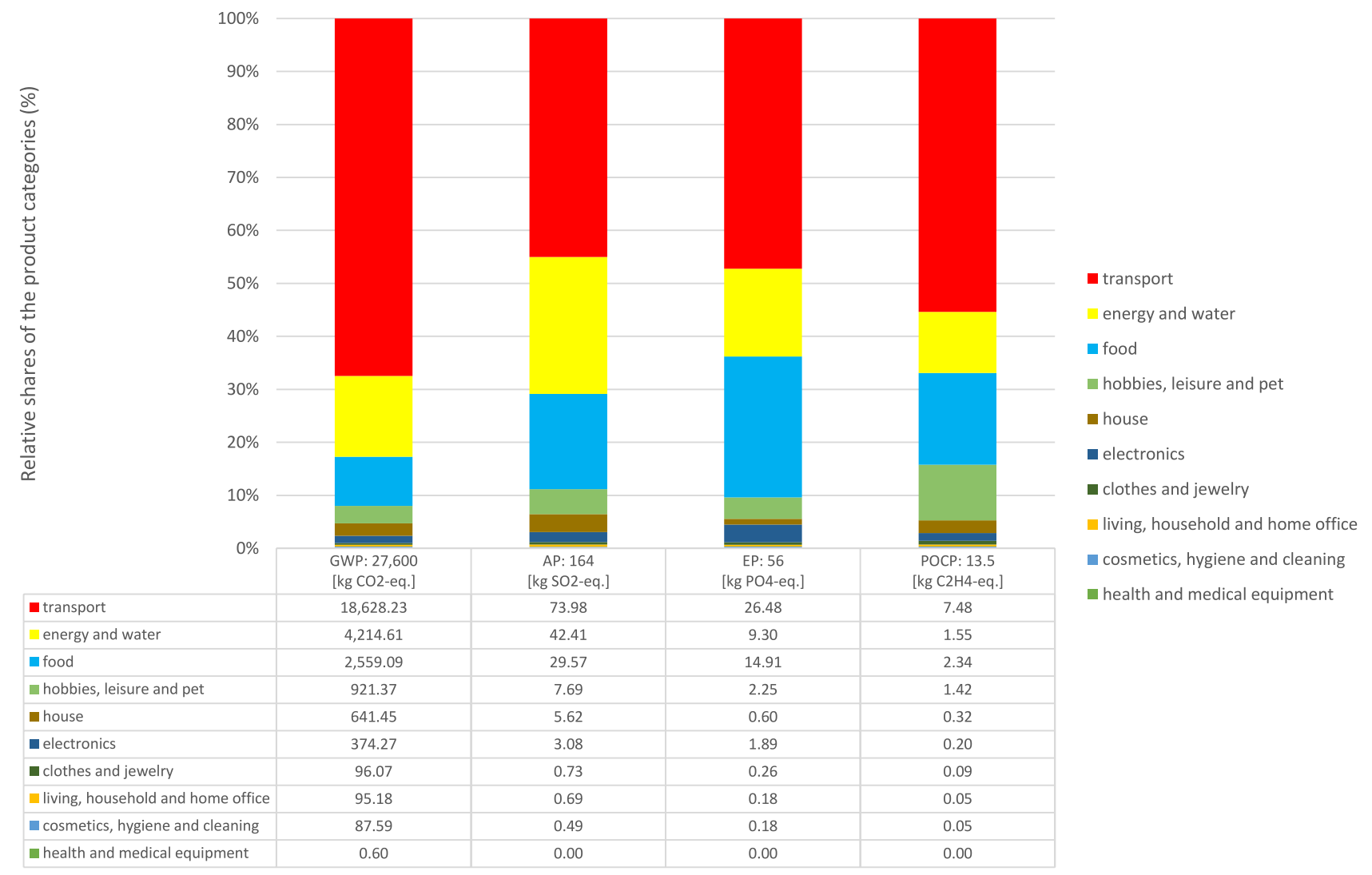

Fig. 4 Baseline results and relative shares of product categories 


\begin{tabular}{|c|c|c|c|c|c|c|c|c|c|c|c|}
\hline \multirow{3}{*}{ 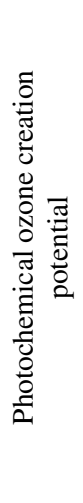 } & 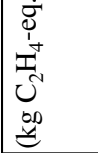 & $\underset{b}{\mathbb{b}}$ & $\stackrel{\oplus}{-}$ & $\stackrel{\infty}{\rightleftarrows}$ & $\stackrel{+}{\stackrel{+}{0}}$ & $\stackrel{m}{\stackrel{0}{0}}$ & $\stackrel{\infty}{\infty}$ & $\overline{\tilde{o}}$ & 隹 & 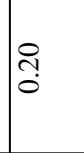 & $\stackrel{5}{0}$ \\
\hline & 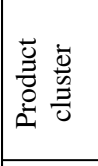 & 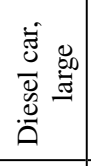 & 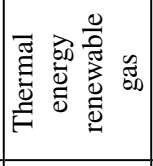 & $\begin{array}{ll}\overrightarrow{0} & 0 \\
3 & 0 \\
0 & 0 \\
0 & 0 \\
0\end{array}$ & 苞 & 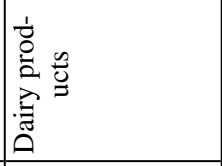 & 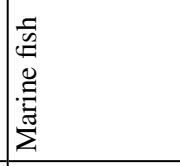 & 苋 & 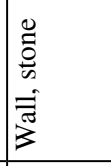 & $\stackrel{0}{\Xi}$ & 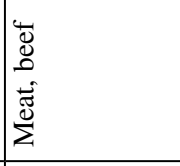 \\
\hline & 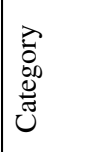 & 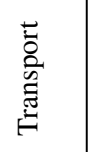 & 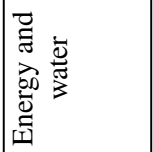 & 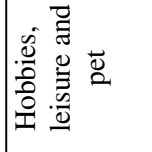 & 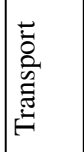 & $\begin{array}{l}\overline{0} \\
0 \\
0 \\
\end{array}$ & 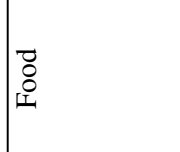 & $\begin{array}{l}\overrightarrow{0} \\
0 \\
0\end{array}$ & 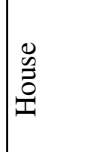 & $\begin{array}{l}\overline{0} \\
0 \\
0\end{array}$ & $\begin{array}{l}\square \\
0 \\
\circ\end{array}$ \\
\hline \multirow{3}{*}{ 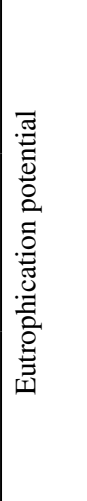 } & 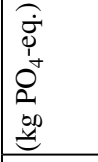 & $\begin{array}{l}\dot{D} \\
\tilde{\lambda} \\
\vec{\lambda}\end{array}$ & $\begin{array}{l}\text { if } \\
\infty \\
\infty\end{array}$ & $\underset{\sim}{\sigma}$ & $\underset{i}{\tilde{i}}$ & $\overrightarrow{\vec{c}}$ & $\stackrel{\text { }}{\stackrel{n}{-}}$ & $\stackrel{\mathscr{F}}{\sim}$ & 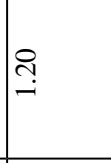 & $\underset{\sigma}{\sigma}$ & $\tilde{\tilde{o}}$ \\
\hline & 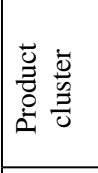 & 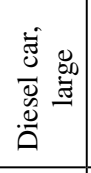 & 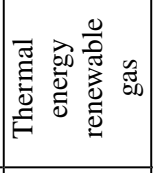 & 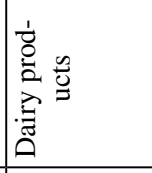 & 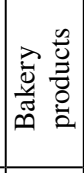 & 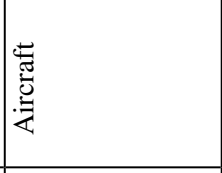 & 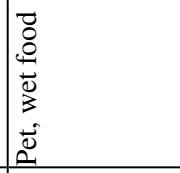 & 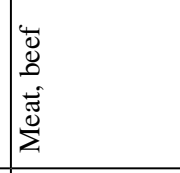 & 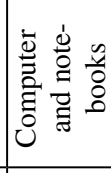 & ن & 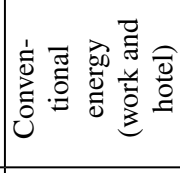 \\
\hline & 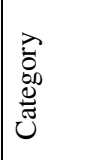 & 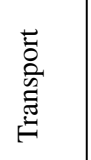 & 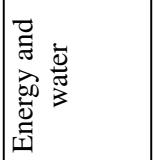 & $\begin{array}{l}\ddot{0} \\
0 \\
\end{array}$ & $\begin{array}{l}\ddot{0} \\
0 \\
0\end{array}$ & 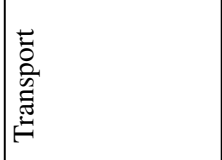 & 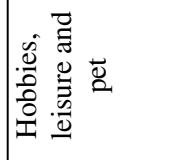 & $\begin{array}{l}\overrightarrow{0} \\
0 \\
0\end{array}$ & 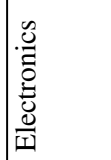 & $\mid \begin{array}{l}\overrightarrow{8} \\
0 \\
1\end{array}$ & 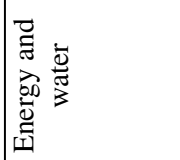 \\
\hline \multirow{3}{*}{ 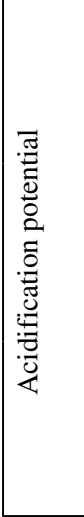 } & 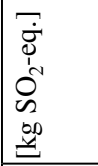 & $\begin{array}{l}\text { f } \\
\text { fi }\end{array}$ & $\begin{array}{l}\hat{y} \\
\infty \\
\infty \\
m\end{array}$ & $\stackrel{ \pm}{\beth}$ & $\underset{\sim}{\infty}$ & חi & $\mid \begin{array}{l}\dot{+} \\
\stackrel{+}{+}\end{array}$ & $\stackrel{+}{\stackrel{m}{-}}$ & 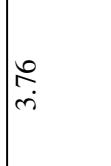 & $\stackrel{\leftrightarrow}{\mathscr{z}}$ & $\stackrel{0}{\stackrel{2}{2}}$ \\
\hline & 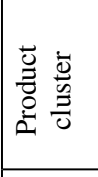 & 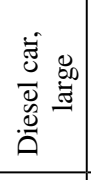 & 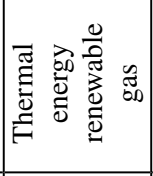 & 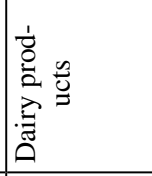 & 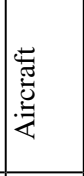 & 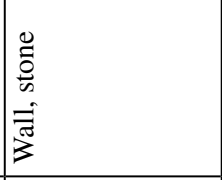 & 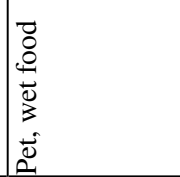 & 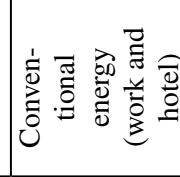 & 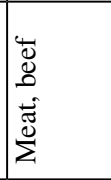 & 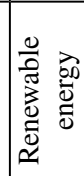 & 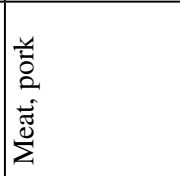 \\
\hline & 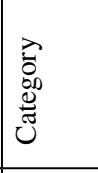 & 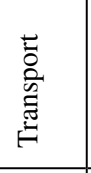 & 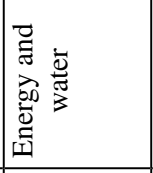 & $\begin{array}{l}\overrightarrow{0} \\
0 \\
I\end{array}$ & 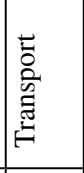 & 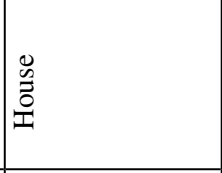 & 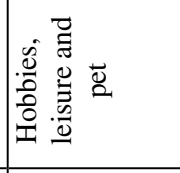 & 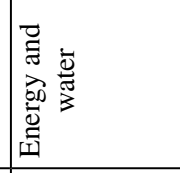 & $\begin{array}{l}\overline{8} \\
8 \\
1\end{array}$ & 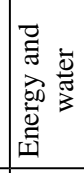 & 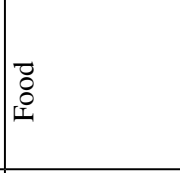 \\
\hline \multirow{3}{*}{ 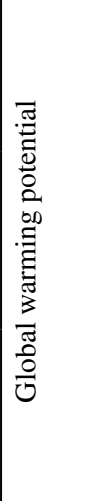 } & 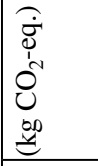 & $\begin{array}{l}\text { } \\
m_{0} \\
\underbrace{2}_{0}\end{array}$ & 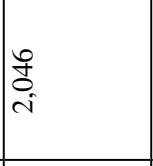 & $\underset{-\infty}{\infty}$ & $\underset{-}{\stackrel{0}{0}}$ & $\stackrel{m}{m}$ & 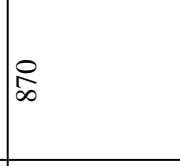 & $\stackrel{\infty}{0}$ & 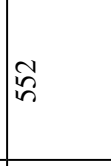 & $\stackrel{\infty}{\infty}$ & ஓి \\
\hline & 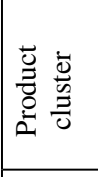 & 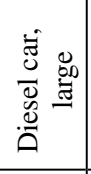 & 竞 & 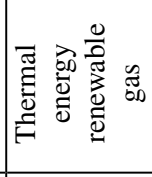 & 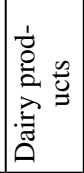 & 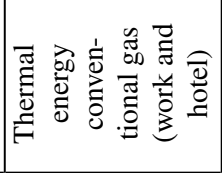 & 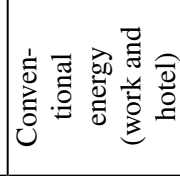 & 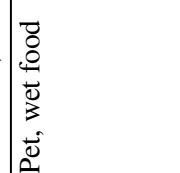 & 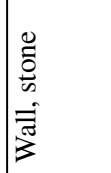 & 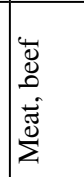 & 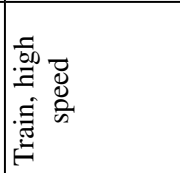 \\
\hline & 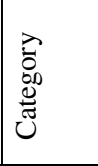 & 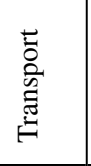 & 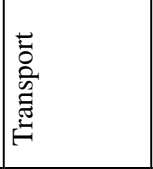 & 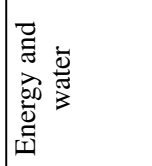 & $\begin{array}{l}\overline{0} \\
0 \\
1\end{array}$ & 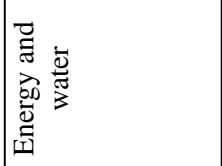 & 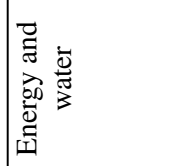 & 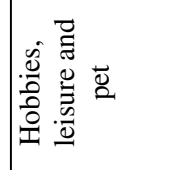 & 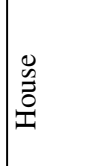 & $\begin{array}{l}\overline{0} \\
0 \\
0\end{array}$ & 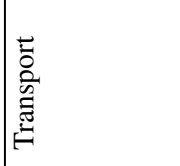 \\
\hline 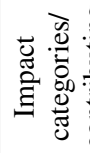 & 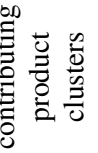 & - & $\mathrm{a}$ & $m$ & t & n & 0 & Ir & $\infty$ & a & 으 \\
\hline
\end{tabular}


Table 2 Extract of the consumption inventory-top contributor

\begin{tabular}{|c|c|c|c|c|c|}
\hline Main category & Product cluster & Yearly consumption-BS & Yearly consumption-OS & Difference (\%] & Unit \\
\hline Transport & Diesel car, medium & 0 & 742 & Not applicable & $\mathrm{km}$ \\
\hline Transport & Diesel car, large & 40,534 & 0 & Not applicable & $\mathrm{km}$ \\
\hline Transport & Hybrid car & 0 & 7,246 & Not applicable & $\mathrm{km}$ \\
\hline Transport & Train, local & 0 & 7,497 & Not applicable & $\mathrm{km}$ \\
\hline Transport & Train, high speed & 11,445 & 28,901 & $+153 \%$ & $\mathrm{~km}$ \\
\hline Transport & Bus & 0 & 72 & Not applicable & $\mathrm{km}$ \\
\hline Transport & Aircraft & 18,559 & 0 & Not applicable & $\mathrm{km}$ \\
\hline Energy and water & Renewable energy & 2,097 & 614 & $-71 \%$ & $\mathrm{kWh}$ \\
\hline Energy and water & $\begin{array}{l}\text { Conventional energy (work and } \\
\text { hotel) }\end{array}$ & 4,385 & 0 & $0 \%$ & $\mathrm{kWh}$ \\
\hline Energy and water & Thermal energy renewable gas & 80,287 & 59,512 & $-26 \%$ & MJ \\
\hline Energy and water & $\begin{array}{l}\text { Thermal energy conventional gas } \\
\text { (work and hotel) }\end{array}$ & 20,072 & 0 & $0 \%$ & MJ \\
\hline Energy and water & Water use & 52,894 & 22,379 & $-58 \%$ & $\mathrm{~kg}$ \\
\hline Food & Dairy products & 82 & 6 & $-93 \%$ & $\mathrm{~kg}$ \\
\hline Food & Meat, beef & 14 & 0 & Not applicable & $\mathrm{kg}$ \\
\hline Food & Coffee & 15 & 12 & $-21 \%$ & $\mathrm{~kg}$ \\
\hline Food & Wine & 48 & 37 & $-23 \%$ & $\mathrm{~L}$ \\
\hline Food & Marine fish & 17 & 10 & $-40 \%$ & $\mathrm{~kg}$ \\
\hline Food & Vegetables (domestic) & 43 & 117 & $+171 \%$ & $\mathrm{~kg}$ \\
\hline Food & Bakery products & 66 & 56 & $-16 \%$ & $\mathrm{~kg}$ \\
\hline Food & Fruit (domestic) & 3 & 10 & $+239 \%$ & $\mathrm{~kg}$ \\
\hline Hobbies, leisure and pet & Pet, wet food & 365 & 144 & $-61 \%$ & $\mathrm{~kg}$ \\
\hline Hobbies, leisure and pet & Pet, dry food & 35 & 21 & $-40 \%$ & $\mathrm{~kg}$ \\
\hline Hobbies, leisure and pet & Pet, vegetables & 0 & 30 & Not applicable & $\mathrm{kg}$ \\
\hline Hobbies, leisure and pet & Pet, rice & 0 & 6 & Not applicable & $\mathrm{kg}$ \\
\hline
\end{tabular}

Life-LCA results, the baseline scenario shares are around 10-20\% lower for the impact category AP and EP and 5\% for GWP and POCP, since Dirk bought his meat in the supermarket until he started hunting in 2015.

Together, the three addressed product categories ("transport," "energy and water," and "food") have a total share of around $90 \%$ for GWP, AP, and EP and $85 \%$ for POCP.

Contributions from other product categories such as "hobbies, leisure, and pet" downwards to "health and medical equipment" are not as significant in regard to the overall results $(0-10 \%)$. However, in the following, the major contributors for GWP of each product category are described to show hotspots with a great optimization potential, as well as demonstrate how detailed a human's footprint can be analysed with the Life-LCA approach:

- In the product category "hobbies, leisure, and pet," his current dog is responsible for $76 \%$ of the $\mathrm{CO}_{2}$-eq. emissions. Especially pet food (industrial meat and wet dog food) shows a significant contribution. More than half (57\%) of Dirk's total meat consumption is due to his dog.
Further, the product cluster hunting has high impacts (10\%) due to ammunition (highest share with 95\%), weapons, several accessories, and a pair of binoculars. The relative share of this product category in regard to the baseline results is $3.3 \%$.

- In the product category "house," the product cluster "wall stones" has the major contribution with $86 \%$, followed by "flooring carpets" $(5 \%)$. The relative share in regard to the baseline results is $2.3 \%$.

- In the product category "electronics," devices used for interaction (computer and notebooks) have the highest impact (33\%). The relative share is $1.4 \%$.

The following four product categories have a share of around $0-1 \%$ in regard to the overall baseline results:

- Product category "clothes and jewellery": polyester and cotton clothes contribute one-third to GWP, followed by his sports shoes $(4 \%)$.

- Product category "living, household, and home office": furniture (including the product cluster "soft furniture," 
Table 3 LCIA results for the baseline and optimized scenario

\begin{tabular}{|l|l|l|l|l|}
\hline & $\begin{array}{l}\text { GWP }\left(\mathrm{kg} \mathrm{CO}_{2^{-}}\right. \\
\text {eq })\end{array}$ & $\begin{array}{l}\mathrm{AP}(\mathrm{kg} \\
\mathrm{SO}_{2^{-}} \\
\mathrm{eq})\end{array}$ & $\begin{array}{l}\mathrm{EP}(\mathrm{kg} \\
\mathrm{PO}_{4^{-}} \\
\text {eq. })\end{array}$ & $\begin{array}{l}\mathrm{POCP}(\mathrm{kg} \\
\left.\mathrm{C}_{2} \mathrm{H}_{4} \text {-eq. }\right)\end{array}$ \\
\hline $\begin{array}{l}\text { Baseline scenario } \\
\text { Optimized sce- } \\
\text { nario } \\
\text { Difference }(\%)\end{array}$ & \begin{tabular}{l}
27,600 \\
\hline
\end{tabular} & 164 & 56 & 13.5 \\
\hline
\end{tabular}

"hard furniture metal," hard furniture, "wood") has the largest share with approximately $44 \%$.

- Product category "cosmetics, hygiene, and cleaning": tissue papers have the highest impact (46\%), followed by Dirk's toothpaste (26\%) and detergents (solid and laundry $=15 \%$ ).

- Product category "health and medical equipment": dominated by the eyeglass lenses (33\%) and bandaging (29\%).

Supplementary material SM1 (see SM1: 1. LCIA results) shows all baseline scenario results in detail for every product category and cluster.

Table 1 shows the top 10 product clusters for all studied impact categories. Renewable energies and certain food products appear in the top 10 results for AP and EP. In the impact category GWP, transport and traditional energy sources dominate. This indicates that optimization only according to GWP aspects could increase the pressure towards other environmental effects. For example, the consumption of more plant-based food products (e.g., $1 \mathrm{~kg}$ regional vegetables) can have positive impacts with regard to the impact category GWP, but results in higher proportions in the impact category EP (e.g., due to fertilizer use) when comparing it to some meat products (e.g., $1 \mathrm{~kg}$ beef). Further, Table 1 shows that two out of ten top contributors for GWP and AP are related to food products (most dominant: dairy products). For EP, four out of ten top contributors are related to food and for POCP even half of the displayed product clusters. Thus, reducing the consumption of primarily dairy products, marine fish and coffee could make significant changes for all impact categories, but especially POCP. Likewise, a reduction in bakery and beef products could reduce the impacts of the category EP. When conducting a hotspot analysis considering all impact categories, the top three adjusting screws for optimization are the product clusters "diesel car, large"; "thermal energy renewable gas"; and "dairy products" (in this order). It is important to note that Dirk was already using renewable energy in the baseline scenario ("thermal energy renewable gas"). Dirk tried to optimize his lifestyle based on the results of the baseline scenario. The associated impacts of this optimization are demonstrated in a detailed analysis in the next chapter.

\subsection{Optimized scenario}

The baseline results shown in Sect. 3.2 revealed contributions and hotspots of Dirk's current consumption patterns. By his own choice and based on individual recommendations from two German environmental NGOs, Dirk significantly changed his lifestyle and applied improvement measures in his $49^{\text {th }}$ life year to reduce his environmental impacts as much as feasible. Measures included, for example, having web meetings instead of face-to-face meetings, disbanding flights, change of car, shifting to an almost vegan diet, different dog feed, and applying energy efficiency measures in the house. Table 2 shows exemplarily inventory changes for the top contributors (see SM1: "2. Consumption inventory," for a detailed listing of all inventory changes).

After implementing these changes, a second data collection of his consumption was performed and yearly impacts
Table 4 Changes of the GWP results for the baseline and optimized scenario

\begin{tabular}{llll}
\hline Product category & $\begin{array}{l}\mathrm{GWP}\left(\mathrm{kg} \mathrm{CO}_{2} \text {-eq.) }\right. \\
\text { (baseline scenario) }\end{array}$ & $\begin{array}{l}\mathrm{GWP}\left(\mathrm{kg} \mathrm{CO}_{2} \text {-eq.) }\right. \\
\text { (optimized scenario) }\end{array}$ & Difference (\%) \\
\hline Transport & 18,628 & 3,484 & -81 \\
Food & 2,560 & 738 & -71 \\
Hobbies, leisure, and pet & 921 & 469 & -49 \\
Clothes and jewellery & 96 & 70 & -28 \\
Cosmetics, hygiene, and cleaning & 88 & 70 & -20 \\
Energy and water & 4,214 & 3,418 & -19 \\
House & 641 & 641 & 0 \\
Electronics & 374 & 381 & +2 \\
Health and medical equipment & 0,6 & 0.75 & +20 \\
Living, household, and home office & 95 & 230 & +59 \\
Sum & $\approx 27,600$ & $\approx 9,500$ & -66
\end{tabular}


calculated. As shown in Table 3, Dirk achieved a significant reduction for GWP (66\%) and AP, EP, and POCP (60\%). The results for his $49^{\text {th }}$ life year have a relative share of around $0.8 \%$ regarding the Life-LCA results. Under the assumption of a yearly average impact of $9.5 \mathrm{t} \mathrm{CO}_{2}$-eq. since his birth, Dirk would have theoretically reached the same amount of $9.5 \mathrm{t} \mathrm{CO}_{2}$-eq. emissions on his $120^{\text {th }}$ birthday as he already emitted on his $49^{\text {th }}$. Further, taking his Life-LCA results as a base (see Sect. 3.1) and assuming a continued constant impact of $9.5 \mathrm{t} \mathrm{CO}_{2}$-eq. per year from his $50^{\text {th }}$ life-year onwards, until his statistically expected death (78.5 years), he would emit around 1,420 $\mathrm{t} \mathrm{CO}_{2}$-eq. until his end of life $(-22 \%$ in regards to the extrapolation described in the LifeLCA scenario in Sect. 3.1).

SM1, Tables 2 and 4 provide further details on where and how reductions were achieved for GWP. As displayed, travelled kilometres could be reduced by far the most $(-35 \%)$, e.g., due to more web meetings and switching to trains, instead of using his former diesel SUV and flights. Compared to the baseline scenario, the total share of train rides increased by $61 \%$ to now $77 \%$. All distances up to $30 \mathrm{~km}$ were carried out with a hybrid car electrically instead of the former SUV. Just one long-distance trip (holiday) was carried out in combined operation (hybrid car) using electricity and petrol. His changed mobility behaviour reduced GWP and AP by around $82 \%$ and EP and POCP slightly lower with $79 \%$.

Figure 5 shows that in the baseline scenario (BL), the product category "transport" dominated all impact categories with relative shares from $45 \%$ to $65 \%$, whereas in the optimized scenario (OL), "energy and water" is predominant for GWP (35\%), AP (45\%), and EP (30\%) by adding up 10\% to $25 \%$. Besides, the relative share of the category "transport" for POCP $(\mathrm{OS}=30 \%)$ decreased around $25 \%$ and is now nearly equal to "food" (25\%) and "energy and water" (22\%). Consequently, "food" is the second dominant product category before "energy and water" for POCP, which is the exception.

The product category "energy" improved through the house's energy-saving measures (e.g., replacing windows and heating system) around $20-25 \%$ in all impact categories. GWP was reduced ( $-71 \%$ ) (see Table 4 ) by switching to an almost vegan diet, except for self-shot game and the consumption of small amounts of dairy products. His meat consumption was mainly substituted by eating three times more fruits and vegetables (see Table 2). The consumption of game meat hunted by himself was in line with the criteria and principles for sustainable wildlife management to help control wildlife populations within the ecosystem (Schmidt Rivera et al. 2014) and was therefore included burden-free

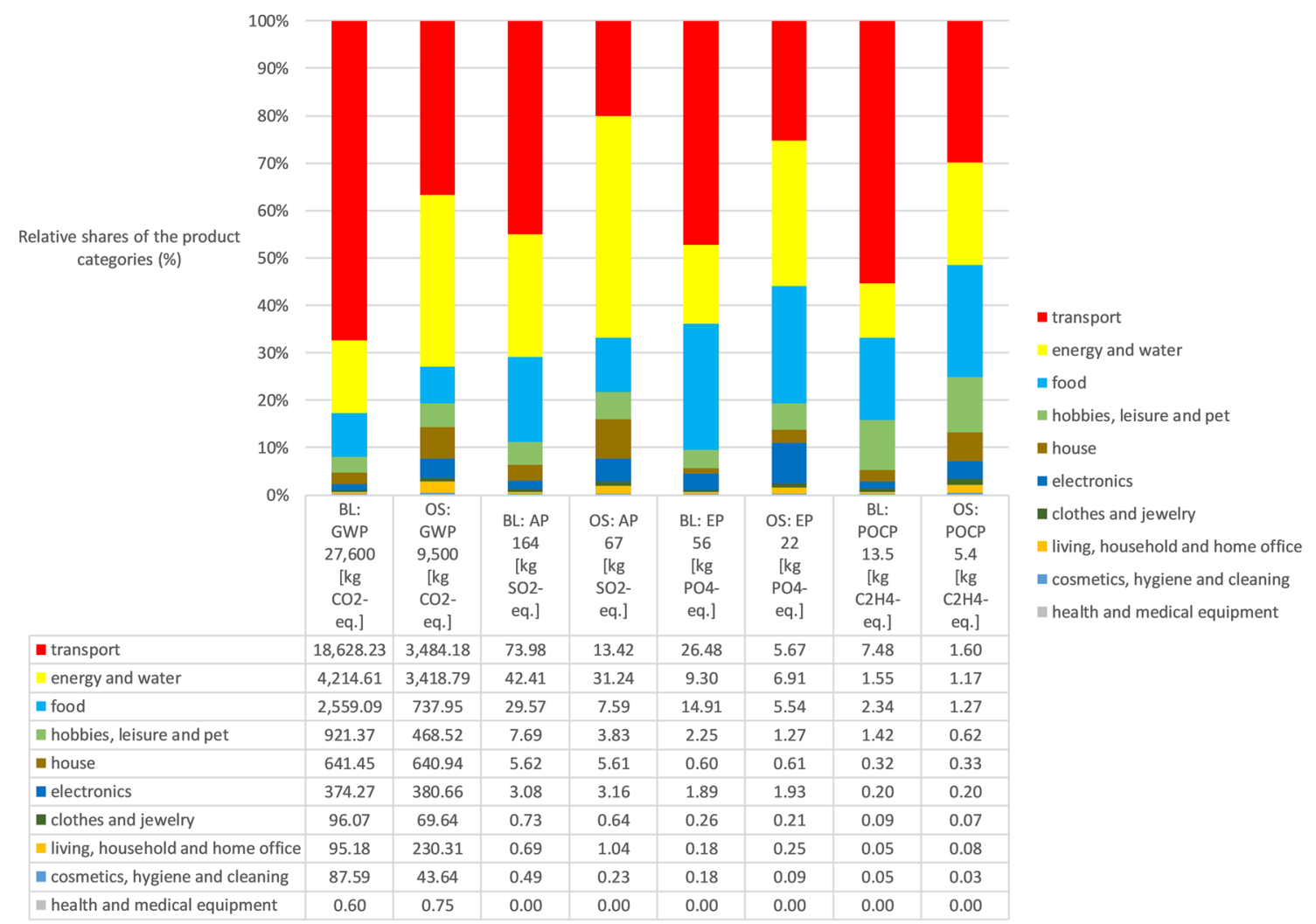

Fig. 5 Comparison of the baseline (BL) and optimized (OS) scenario results and relative shares of product categories 
(except for the hunting burden as such). In a sustainable society, it is not suitable that many people go hunting by themselves. Dirk's hunting activity should be seen as an individual leisure activity and niche option for people with a hunting license, which provides him and a few others (e.g., family members or close friends) in exceptional cases with meat. A meat-reduced or vegan diet should be favoured. His new diet also led to AP (-74\%) and EP (-62\%) reductions.

Dirk did not reduce coffee and marine fish consumption to zero, even though both products were hotspots in "food" with a share of around $40 \%$. Therefore, especially for POCP, the food-related reduction is the lowest with around $45 \%$. Several smaller and less prominent measures, like reducing the consumption of nuts, further improved the GWP. In the baseline scenario, dairy products contributed most to food's GWP, followed by meat and coffee. In the optimized scenario, dairy products are still dominant, but their consumption and associated impact decreased significantly $(-93 \%)$.

The GWP of Dirk's dog was reduced by half through switching to feed with self-shot game, vegetables, organ meats, and food leftovers. However, the dog's food intake still accounts for nearly one-third of Dirk's foodrelated GWP.

Table 4 documents that Dirk managed to improve in the six most relevant product categories, which account for $96 \%$ of his GWP results in the baseline scenario. The highest reductions with respectively $81 \%$ and $71 \%$ were achieved in the product categories "transport" and "food," while in the product category "energy and water," only a smaller reduction of around $20 \%$ was calculated. The impacts caused by the product categories "house" and "electronics" remained roughly at the same level, due to no changes in the infrastructure of the house and an insignificant increase from buying a few bulbs and batteries for the product category "electronics". The impacts related to the product categories "health and medical equipment" and "living, household, and home office" rose by $20 \%$ and $59 \%$ respectively (please note that the overall results of both product categories are insignificantly low), due to particular purchases (e.g., furniture and household ware for the product category "living household and home office" or special synthetic glasses and more earplugs for the product category "health and medical equipment") in the monitoring period, which were partly necessary to achieve reductions in other product categories. As an example, Dirk switched from commercial mineral water to tap water (reduction in the product category "food") and therefore bought equipment and cartridges for a water bubbler (increase in the product category "living, household, and home office"), which are mainly made of aluminium. This efficiency measure from Dirk can be seen as an example of the rebound effect as the enhanced usage of the water bubbler, increased all studied impact categories (e.g., +15
$\%$ (EP) and $+35 \%$ (GWP) in the optimized scenario for the product category "living household and home office").

\section{Discussion}

This chapter critically examines the case study results (see Sect. 4.1) by discussing various limitations, identified challenges, and associated uncertainties regarding the Life-LCA method (see Sect. 4.2). Further, Sect. 4.3 compares the case study and UBA carbon calculator results to evaluate their plausibility and highlight differences in their approaches.

\subsection{General discussion of the results}

In the optimized scenario, the high reduction in some product categories compared to others can partly be explained by the fact that short-term products instead of long-lasting products were used, in which changing consumption patterns result in a direct impact (e.g., food products).

For instance, following the linear depreciation approach, the results for the baseline and optimized scenario in the product category "house" (e.g., a new door out of glass) and "electronics" (e.g., laptop) stayed nearly the same as the depreciation of environmental impacts from long-living products over their reference service life result in the same yearly impacts. The product use stage was not considered to avoid double-counting of environmental impacts (due to a separate electricity and water consumption coverage). Moreover, a more efficient use phase (e.g., a newer refrigerator or a better-insulated house) is reflected by reductions in the category "energy" or "water."

The individual use ratio was applied as the allocation approach to calculate consumption rates in the case of multiple product use by different persons. Therefore, long-lasting and shared products (e.g., house, television), which have a high burden per product unit, show low impacts ("house" or "electronics" have 0-5\% in all studied impact categories in the baseline and Life-LCA scenario) because of the chosen allocation approach, which allocates total burdensfollowing the Life-LCA concept and scope to assess a single person-to several persons. This indicates that the house's construction parts (e.g., bricks or windows) can be neglected in the case of Dirk due to the partitioning of the impacts among different users and years. However, housing might be a relevant impact contributor in other future individual Life-LCAs under different conditions (e.g., big house with fewer family members). However, it has to be kept in mind that due to the depreciation of environmental impacts, the house's energy consumption is of great significance.

The loss of product value during subsequent use (e.g., second-hand products) was not considered because different appreciation values for different products are necessary 
and a robust method still needs to be developed. For many consumer goods, the loss in value at the beginning of their use is greater than at the end. This fact is not as relevant if the product is used until the end of its life. However, if Dirk sells a once-bought good or he decides to buy second-hand goods, the question of a suitable allocation quickly arises. Such depreciation/appreciation models could be integrated into future studies for different product categories to create incentives to buy second-hand goods. Further, it could be interesting to look into Life-LCA in the context of a circular economy to increase sharing and re-use approaches. Economically speaking, houses and properties most likely increase in value (depending on maintenance and location), but old houses have a poorer rating regarding energy efficiency. In this sense, compared to many consumer goods, as described above, a second-hand (old) house could increase someone's footprint over the years due to higher energy consumption. Dirk could effectively lower his footprint when selling his current (old) house and renting an apartment with high energy efficiency in the city. This could reduce mainly the product category "energy and water," but also "transport" (assuming that Dirk uses more public transport in the city), "living household and home office" (e.g., less furniture), and "hobbies, leisure, and pet" (e.g., no gardening tools).

Changing consumption patterns can also lead to burdenshifting between impact categories and show that the choice of optimization measures should not only be based on GWP. For instance, substituting meat for plant-based food products can positively impact GWP but sometimes results in higher proportions in other impact categories (e.g., EP) (as described in Sect. 3.2). Further, consuming self-hunted meat instead of industrial meat also reduced the GWP but most likely caused toxicological impacts due to the used bullets (Tranel 2009; Arnemo et al. 2016), which are not covered by the study.

Substituting Dirk's dog with another pet, which has a lower environmental footprint, was not considered in this study. Reducing the dog's impact could be achieved by minimizing overfeeding, finding alternative food sources, and increasing the faeces collection rate (Okin 2017; Yavor et al. 2020). Further, if pets are not considered a medical or mental treatment, but instead considered a hobby-which is probably most often the case-it should be allowed to discuss to refrain from pets at all, as it is allowed to propose to refrain from other healthy but impacting activities (e.g., skiing or golfing as a hobby).

A reduction of around $60 \%$ for all impact categories by the taken measures (optimized scenario) underlines the need to strengthen environmental education and focus more on consumer behaviour and patterns. As recently pointed out by Büchs et al. (2018), providing just general information without considering individuals' specific background (e.g., social/cultural influences or specific consumer behaviours) is relatively ineffective in motivating people to substantial behavioural changes. Performance tracking especially seems to play a significant role in achieving positive long-term effects (Abrahamse et al. 2005; Büchs et al. 2018). Further, the high effort of data collection (e.g., the tangible action of getting everything out of a cupboard or closet for counting) raises awareness of the personal consumption and therefore contributes to "environmental education" of the individual, as the study object is actively investing time and therefore building a close relationship to the study and its results. This study showed that an accurate data collection with the Life LCA bottom-up approach is a time-consuming process and requires the study object's significant intrinsic motivation if high-quality results are the aim.

Besides, this study did not consider the indirect impacts of Dirk's decisions as a CEO, which could potentially influence his company's and employee's footprint as the individual Life-LCA's scope is to find essentially in the impact assessment of sustainable consumption from Dirk. The company's decisions are mainly discussed and then decided by different persons in a team. Again, the question of allocation between the different team or board members and each decision and associated impacts arises. A hybrid Life-LCA/ O-LCA or product-related LCA-approach could be an option for future studies, e.g., if a company's size, product, and associated impacts are far-reaching and clearly attributable to a CEO's decision.

\subsection{Discussion of the methodological challenges and uncertainties of Life-LCA}

Based on the experience of the first case study presented here, encountered uncertainties, their consideration in this case study, and potential solutions (if the authors decided to exclude a specific aspect) are summarized in Table 5.

Goermer et al. (2019) already listed several Life-LCA challenges from a theoretical perspective in their method paper. Therefore, in addition to Table 5, the following bullet points discuss some of these presented methodological core challenges and associated uncertainties in detail:

- Consideration of human development and changing consumption behaviours

Modelling Dirk's whole life and especially his past consumption leads to high uncertainties as a distinguished consumer behaviour can also be assumed for other product categories, besides the ones described in Sect. 2.3.1 ("transport", "house", "energy and water", "food" and "hobbies, leisure and pet") and included in this case study.

Whereas the "childhood and youth stage" (0-17 years) was taken into account with a $50 \%$ lower yearly consumption as in the baseline scenario (see Sect. 2.2), the 
The International Journal of Life Cycle Assessment (2021) 26:1847-1866

1861

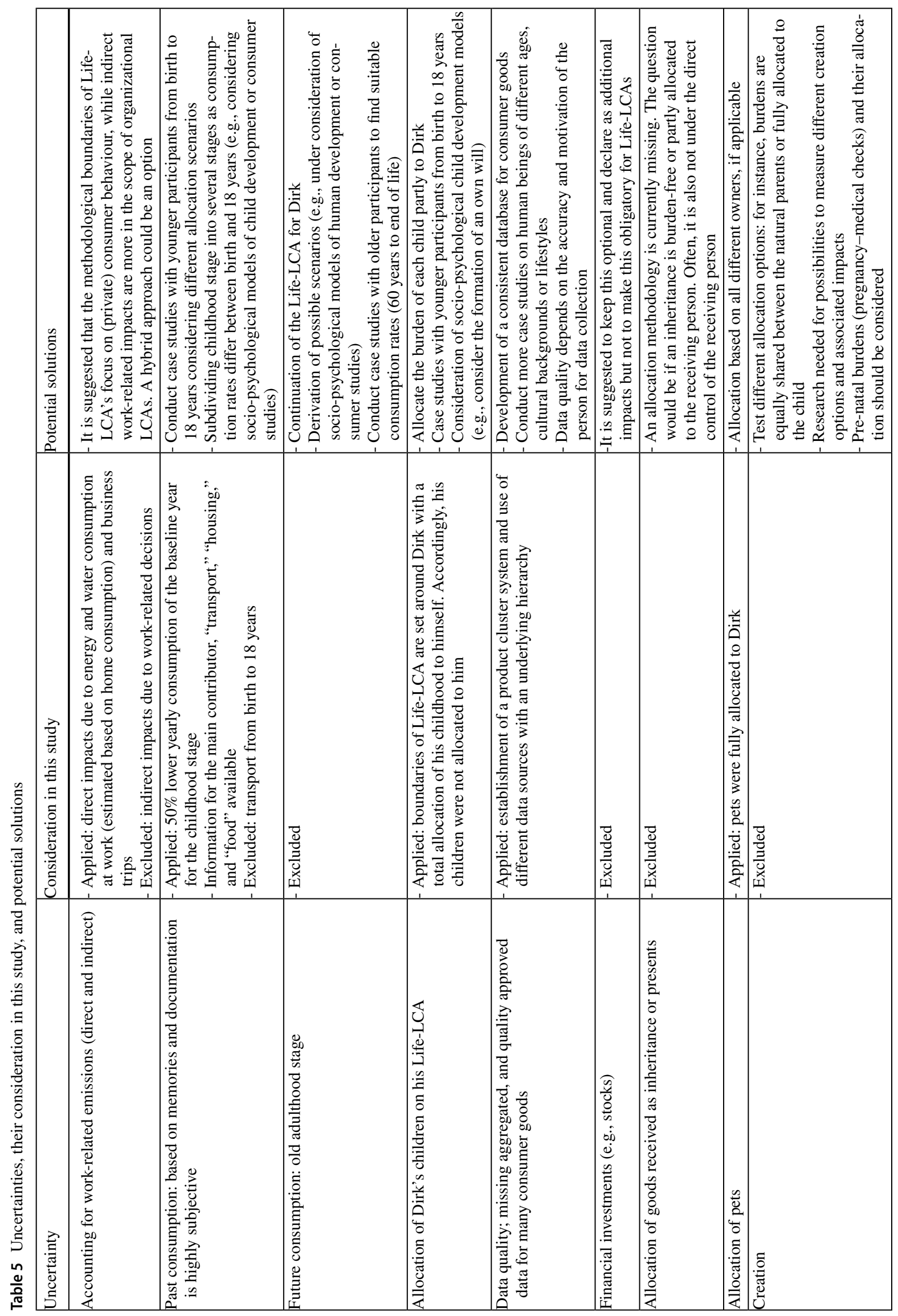

Springer 


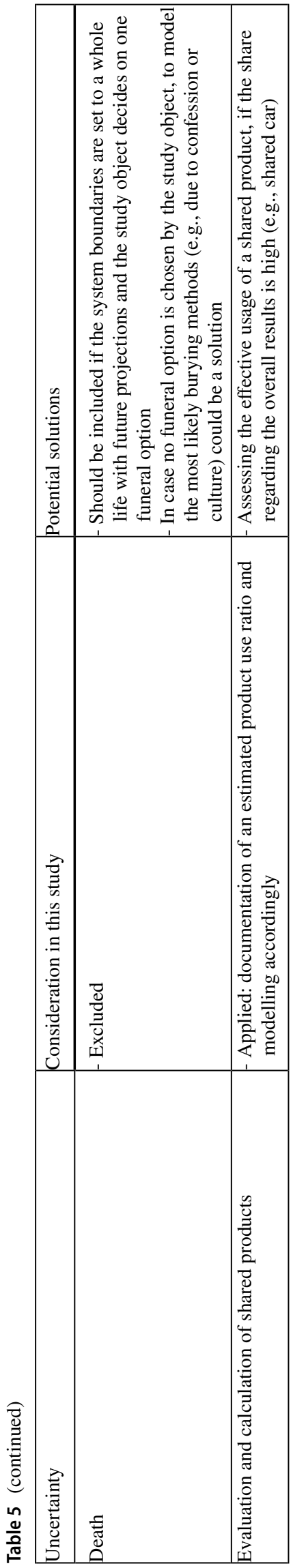

"old adulthood stage" (60 years to end of life) was excluded in this case study, as it would have involved further uncertainties. A sensitivity analysis with $25 \%$ lower and $75 \%$ higher yearly consumption as in the baseline scenario for the "childhood and youth stage" results in a $2-5 \%$ difference (compared to the overall results) from the $50 \%$ lower yearly consumption scenario applied in this study.

For the "childhood and youth stage", where possible, e.g., due to past documentation or the memory of Dirk, more specific data were considered, which face, however, the challenge of subjectivity (e.g., different memories). Thus, a new methodological concept needs to be established in the future. The authors acknowledge that the childhood phase assumption is a very simplified approach and recommend performing additional case studies covering different life stages to fill this gap. The reconstruction of past life consumption behaviour (retrospective) or future years (prospective) remains a general challenge for Life-LCA. Therefore, future research should focus on case studies (including different scenarios) with younger or older participants to consider in detail other life stages to gain further knowledge in regards to appropriate consumption rates and develop the methodology and underlying database.

- Determination and delimitation of potential Life-LCA applications

This case study considered the analysis of an individual human being rather than a particular lifestyle. Consequently, all results presented cannot be generalized due to Dirk's individual variables, such as his living situation, country of origin, or his job as a CEO of a company. As soon as several Lifestyle-LCA case studies have been carried out, Dirk could be classified or integrated into one of these approaches based on criteria such as his age, income class, or eating behaviour.

Further, it can be assumed that an individual LifeLCA is more time-consuming than a Lifestyle-LCA concerning data collection and evaluation, as it covers all specific parts of consumption of the study object and does not just focus on specific parts of a particular lifestyle.

- Definition of cut-off criteria for life stages and consumed products

So far, there are no guiding rules or general cut-off criteria, as practical experience and other case studies in the field of Life-LCA are currently missing. The decision to exclude or include a specific product or life stages (e.g., "old adulthood stage" in this case study) can be a question of (a) goal and scope of the study; (b) data availability, uncertainty, and resources for data collection, modelling, and evaluation; and (c) expected contribution to the overall results. 
Concerning the life cycles of Dirk's consumed products, one of the difficulties was the acquisition of specific electricity and water data for individual devices. Energy and water were recorded in total values using the electricity/water meter as it is almost impossible to record the electricity and water consumption of individual devices separately, which would even further increase the effort of data collection. However, this means that (1) the use phase of some products has to be cut off from the modelling to avoid double counting and (2) that the optimization potential of some products is "hidden" in other product categories.

- Allocation of the childhood phase and other sociopsychological interactions between human beings

A more interdisciplinary approach is needed to tackle allocation for childhood and adolescence, which allows determining external influences on consumption patterns. For instance, the products consumed by his children, which Dirk at least partly influences, were excluded in this case study. However, Dirk's childhood was also fully allocated to him. When allocating part of the impacts from his five children's childhood phase to his consumption, his environmental impact would increase. The challenge is to find an appropriate interface between the responsibility of consumption choices of children and their parents. Again, representative case studies with younger participants could provide insights and help to define a reasonable allocation.

\section{- Consideration of creation and death}

Both creation and death were excluded from this case study, although these aspects need to be considered in a comprehensive Life-LCA study. There was no specific information on Dirks creation available. Generally, this life cycle stage could be expected to be of minor relevance. Regarding Dirk's death, the ceremony, biological decay, emissions (e.g., cremation or mercury to air emissions (teeth)), and land use of the funeral could be considered. Keijzer (2017) analysed the environmental impacts of the two funeral options, burial, and cremation through a life-cycle assessment. The results showed no significant difference in the five investigated impact categories. So far, Dirk has not decided on any of these options.

- Collection of complex and diverse consumption data and development of an applicable bottom-up product clustering scheme

Data collection sheets (see TU Berlin website) and a bottom-up product clustering scheme were developed, which can be used in future Life-LCAs. These sheets and schemes are individualized and suit Dirk's consumption behaviour. Thus, they need to be adapted when they are applied to a different human being. Different product categories and clusters related to the respective defined goals and scopes might need to be integrated. For instance, the current product categories represent products consumed by a specific European, but it will not be directly applicable to study subjects of another cultural or social background.

An essential aspect for LCA studies, in general, but also for the new scope Life-LCA, is the time-consuming process for data collection to ensure adequate results. Data collection needs to be integrated over several months (in this case study: 4 months in total) in the study object's daily routine. Data quality depends on the accuracy and motivation of the person. Establishing a manageable balance between necessary detail and the effort of data collection is a crucial factor.

Further, due to the detailed bottom-up approach applied in this study, it is possible to consider burdenshifting effects already at the product/service level to derive strategies about individual consumption patterns.

- Definition of new data quality requirements and rules for inventory calculations

Due to the complexity of consumer behaviour, it was not possible to perform individual product LCAs for all consumed products. Many data on product level were available, as mentioned in Sect. 2.3.1, but only on a generic level (e.g., we know Dirk uses a television, but the brand, company, or origin of all components could not be considered). For some consumed products or product categories, using data on a generic level might be sufficient (e.g., the television) as their overall consumption and associated impact are less significant, whereas for others, even more specific data are needed (e.g., transport means: car).

This also makes data quality a critical issue for Life-LCA. Proper (new) quality criteria need to be defined to control a consistent use of available datasets and, for example, to validate limitations for data acquisition. The development of a consistent database with aggregated datasets for consumer goods is a main task for future improvement of the Life-LCA method. Considering the dependency on LCI/LCIA data and external case studies that often contained just a limited set of impact categories, it was not possible to assess other impact categories like "land use" or "water footprint". Further case studies on human beings of different ages and cultural backgrounds (e.g., European vs. Asian) or specific lifestyles (meat-eater vs. vegan) could help increase data quality and further develop the Life-LCA methodology.

The current status of the GaBi model and associated LifeLCA results can be seen as a first baseline to test the feasibility of the methodological approach from Goermer et al. (2019). Possible adaptations and continuous development could be considered to solve the discussed challenges and associated uncertainties in the future. 
Fig. 6 Comparison of GWP impacts: case study results vs. UBA carbon calculator and data of an average German

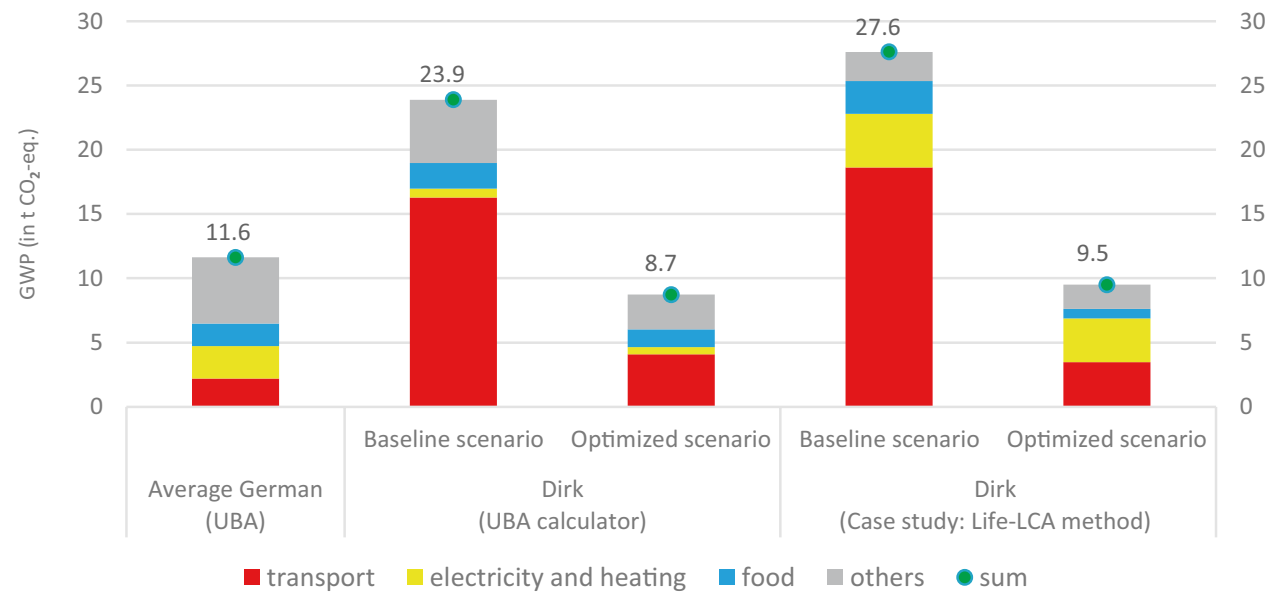

\subsection{Plausibility check of the results with the UBA carbon calculator}

For plausibility reasons and to highlight differences in the approaches, Dirk's Life-LCA results for the impact category GWP of the product categories "electricity and heating," "food," and "transport" are compared with the calculated results of the UBA's online carbon calculator. Further, data of an average German are shown in relation to the case study (UBA 2019) (see Fig. 6).

According to the UBA footprint calculator and the LifeLCA method, Dirk's GWP impacts for the baseline scenario were more than double compared to an average German, primarily due to his travel behaviour (as seen in the product category "transport"). After optimization, his GWP impact was around 20\% lower than the average German.

The UBA calculator present slightly higher values for both scenarios. This can be explained by a more detailed, personalized bottom-up approach and a greater variety of considered products for the Life-LCA method. For instance, Dirk's energy consumption for hotel stays and time spent at work is not considered in the UBA calculator; therefore, this category's results show lower values than the Life-LCA case study (see Fig. 6). Transport data were collected userspecific (e.g., the kilometre travelled by plane per year) with the UBA-calculator. However, for the optimized scenario, it was not possible to differentiate between times of a purely electric or petrol operation of Dirk's hybrid car (e.g., Dirk drove electrically for all distances up to $30 \mathrm{~km}$; see Sect. 3.3), which led to higher values for the UBA calculator. The UBA calculator's product category "food" was covered with generic data asking for the analyzed person's weight, diet type (meat-eater, vegetarian, vegan), and whether the consumed food is produced conventional or organic. Consequently, the UBA calculator results show for both scenarios a high deviation (50\%). Also, the environmental impacts of the category "others" for the UBA calculator are estimated by a questionnaire (e.g., average monthly consumer spending or purchasing behaviour (economic vs. generous)). In contrast, "others" is determined specifically within the Life-LCA case study and is based on a subdivided bottom-up product clustering system (see Sect. 2.3.2).

The rather generic questionnaires of the UBA calculator have the purpose of solving the trade-off between the calculator's complexity (and thus, the user's effort to collect and fill in consumer data) and the accuracy of the results. Overall, compared to the applied Life-LCA method in this case study, the UBA calculator has a vastly nontransparent top-down approach, only providing a rough estimation of a person's footprint, neglecting relevant impact categories, such as AP or EP.

\section{Conclusion and outlook}

The first Life-LCA case study was presented in this paper, which gives important insights on applying the Life-LCA method practically (e.g., product clustering, data collection, and calculation). Performance tracking, revealing of reduction potentials, and the identification of possible tradeoffs were possible, as the baseline and optimized results show. Assessing the environmental impacts of a human being beyond GWP, using a bottom-up product clustering approach, under compliance with several allocation rules and an adapted data collection scheme, guarantees consistency, specificity, and comprehensiveness in the field of LifeLCA. This complete picture allowed for better identification of the analyzed person with its caused impacts and led to significant positive changes in the study object's consumption pattern.

Data uncertainties (e.g., data collection from childhood and old adulthood stage) and fundamental methodological challenges remain. Therefore, further research is necessary: from a methodological point of view, this concerns, e.g., 
the refinement of the Life-LCA method (e.g., allocation of the childhood phase), more case studies of persons with different backgrounds and ages, the consideration of specific lifestyles and the identification of final compensation measures. Future studies should also consider additional impact categories (e.g., toxicity or water consumption).

Supplementary Information The online version contains supplementary material available at https://doi.org/10.1007/s11367-021-01924-y.

Funding Open Access funding enabled and organized by Projekt DEAL.

Open Access This article is licensed under a Creative Commons Attribution 4.0 International License, which permits use, sharing, adaptation, distribution and reproduction in any medium or format, as long as you give appropriate credit to the original author(s) and the source, provide a link to the Creative Commons licence, and indicate if changes were made. The images or other third party material in this article are included in the article's Creative Commons licence, unless indicated otherwise in a credit line to the material. If material is not included in the article's Creative Commons licence and your intended use is not permitted by statutory regulation or exceeds the permitted use, you will need to obtain permission directly from the copyright holder. To view a copy of this licence, visit http://creativecommons.org/licenses/by/4.0/.

\section{References}

Abrahamse W, Steg L, Vlek C, Rothengatter T (2005) A review of intervention studies aimed at household energy conservation. J Environ Psychol 25:273-291. https://doi.org/10.1016/j.jenvp. 2005.08.002

Alfredsson EC (2004) "Green" consumption-no solution for climate change. Energy 29:513-524. https://doi.org/10.1016/j.energy. 2003.10.013

Arnemo JMandersen O, Stokke S, et al (2016) Health and environmental risks from lead-based ammunition: science versus socio-politics. EcoHealth 13:618-622. https://doi.org/10.1007/ s10393-016-1177-x

Bach V, Finkbeiner M (2017) Approach to qualify decision support maturity of new versus established impact assessment methodsdemonstrated for the categories acidification and eutrophication. Int J Life Cycle Assess 22:387-397. https://doi.org/10.1007/ s11367-016-1164-z

Beccali M, La gennusa M, Lo Coco L, Rizzo G, (2009) An empirical approach for ranking environmental and energy saving measures in the hotel sector. Renew Energy 34:82-90. https://doi.org/10. 1016/j.renene.2008.04.029

Berg H, Schnurr M, Schipperges M, Glockner H (2018) Erfolgsbedingungen für Systemsprünge und Leitbilder einer ressourcenleichten Gesellschaft. 23-24

Büchs M, Bahaj AS, Blunden L et al (2018) Promoting low carbon behaviours through personalised information? Long-term evaluation of a carbon calculator interview. Energy Policy 120:284-293. https://doi.org/10.1016/j.enpol.2018.05.030

CML-Department of Industrial Ecology (2016) CML-IA Characterisation Factors. https://www.universiteitleiden.nl/en/research/research-output/ science/cml-ia-characterisation-factors. Accessed 15 Oct 2020

Deutsche Bahn (2019) Inside Bahn: Zugreisen: Unterwegs mit 100\% Ökostrom? https://inside.bahn.de/bahn-umwelt-gruen/. Accessed $21 \mathrm{Jul} 2020$
DHP furniture (2019) Product specification for home furniture: material composition: product specification for home furniture

European Commission (2019) Product Environmental Footprint (PEF). https://ec.europa.eu/environment/eussd/smgp/ef_pilots.htm. Accessed $20 \mathrm{Feb} 2020$

European Commission (2018) Product Environmental Footprint Category Rules Guidance. PEFCR Guid Doc 238

Filimonau V, Dickinson J, Robbins D, Huijbregts MAJ (2011) Reviewing the carbon footprint analysis of hotels: Life Cycle Energy Analysis (LCEA) as a holistic method for carbon impact appraisal of tourist accommodation. J Clean Prod 19:1917-1930. https:// doi.org/10.1016/j.jclepro.2011.07.002

Gasverbrauchsrechner (2019) Der statistische Gasverbrauch. https:// www.musterhaushalt.de/durchschnitt/gasverbrauch/. Accessed $14 \mathrm{Jul} 2018$

Glatzer W, Camfield L, MØller V, Rojas M (2015) Global handbook of quality of life: Exploration of well-being of nations and continents Glob Handb Qual Life Explor Well-Being Nations Cont 1-894. https://doi.org/10.1007/978-94-017-9178-6

Goermer M, Lehmann A, Finkbeiner M (2019) Life-LCA: assessing the environmental impacts of a human being — challenges and perspectives. Int $\mathrm{J}$ Life Cycle Assess

Gore T, Alestig M, Ratcliff A (2020) Confronting carbon inequality: putting climate justice at the heart of the COVID-19 recovery

Guinée JB, Gorrée M, Heijungs R et al (2001) Life cycle assessment: an operational guide to the ISO standards III Sci Backgr 692. https://doi.org/10.1300/J082v38n04_05

Hauschild MZ, Wenzel H (1998) Environmental assessment of products. Springer, US

Hertwich EG, Peters GP (2009) Carbon footprint of nations: a global, trade-linked analysis. Environ Sci Technol 43:6414-6420. https:// doi.org/10.1021/es803496a

ISO (2006) ISO 14044:2006 Environmental management—-life cycle assessment-requirements and guidelines

ISO (2014) ISO/TS 14072: Environmental management-life cycle assessment-requirements and guidelines for organizational life cycle assessment

Keijzer E (2017) The environmental impact of activities after life: life cycle assessment of funerals. Int J Life Cycle Assess 22:715-730

Koch P, Salou T (2014) AGRIBALYSE: Methodology. Version 1(1):384

Martínez-Blanco J, Inaba A, Finkbeiner M (2016) Special types of life cycle assessment. Springer, Netherlands

Minkov N, Lehmann A, Finkbeiner M (2020) The product environmental footprint communication at the crossroad: integration into or co-existence with the European Ecolabel? Int J Life Cycle Assess 25:508-522. https://doi.org/10.1007/s11367-019-01715-6

Notter DA, Meyer R, Althaus H-J (2013) The Western lifestyle and its long way to sustainability. Env Sci Technol 4014-4021

Okin GS (2017) Environmental impacts of food consumption by dogs and cats. PLoS ONE 12:1-14. https://doi.org/10.1371/journal. pone. 0181301

Ortega-Egea JM, García-de-Frutos N, Antolín-López R (2014) Why do some people do "more" to mitigate climate change than others? Exploring heterogeneity in psycho-social associations PLoS One 9. https://doi.org/10.1371/journal.pone.0106645

Princen T (2001) Consumption and its externalities: where economy meets ecology. Glob Environ Polit 1:11-30. https://doi.org/10. 1162/152638001316881386

Schanes K, Giljum S, Hertwich E (2016) Low carbon lifestyles: a framework to structure consumption strategies and options to reduce carbon footprints. J Clean Prod 139:1033-1043. https:// doi.org/10.1016/j.jclepro.2016.08.154

Schmidt Rivera XC, Espinoza Orias N, Azapagic A (2014) Life cycle environmental impacts of convenience food: comparison of ready 
and home-made meals. J Clean Prod 73:294-309. https://doi.org/ 10.1016/j.jclepro.2014.01.008

Seppälä J, Posch M, Johansson M, Hettelingh JP (2006) Countrydependent characterisation factors for acidification and terrestrial eutrophication based on accumulated exceedance as an impact category indicator. Int J Life Cycle Assess 11:403-416. https:// doi.org/10.1065/lca2005.06.215

Spiegel (2018) Einer für alle

Statista (2019) Erreichbares Durchschnittsalter in Deutschland laut der Sterbetafel 2016/2018 nach Geschlecht und Altersgruppen. https://de. statista.com/statistik/daten/studie/1783/umfrage/durchschnittlicheweitere-lebenserwartung-nach-altersgruppen/. Accessed 28 Sep 2020

Statistisches Bundesamt (2017) Abfallbilanz (Abfallaufkommen/verbleib, Abfallintensität, Abfallaufkommen nach Wirtschaftszweigen) 2015

Steinemann M, Schwegler R, Spescha G (2017) Grüne Produkte in Deutschland 2017. Marktbeobachtungen für die Umweltpolitik. Umweltbundesamt, Dessau-Roßlau

The Hindu (2018) How one man sets on a path to shrink his carbon footprint

The New York Times (2018) Carbon conscious: how one man is shrinking his footprint

Thinkstep (2018) GaBi Databases: February 2018 Edition - Upgrades \& improvements. 72. https://doi.org/10.1109/RADAR.2011. 5960546
Tranel M (2009) Impacts of lead ammunition on wildlife, the environmentand human health a literature review and implications for Minnesota. 318-337. https://doi.org/10.4080/ilsa.2009.0307

UBA (2019) Klimaneutral leben: Die CO2-Bilanz im Blick. In: 2019. https://uba.co2-rechner.de/de_DE/. Accessed 25 Oct 2019

UBA (2021) Indicator: Greenhouse gas emissions. https://www. umweltbundesamt.de/en/indicator-greenhouse-gas-emissions\# environmental-importance. Accessed 1 Feb 2021

UNEP/SETAC (2015) Guidance on organizational life cycle assessment. Paris

United Nations (2016) The 2030 Agenda for sustainable development. Arsen Res Glob Sustain - Proc 6th Int Congr Arsen Environ AS 2016 12-14

van Oers L, de Koning A, Guinée JB, Huppes G (2002) Abiotic resource depletion in LCA. Road Hydraul Eng Inst 1-75

Wernet G, Bauer C, Steubing B et al (2016) The ecoinvent database version 3 (part I): overview and methodology. Int J Life Cycle Assess 21:1218-1230. https://doi.org/10.1007/s11367-016-1087-8

Yavor KM, Lehmann A, Finkbeiner M (2020) Environmental impacts of a pet dog: an LCA case study. Sustainability 12:3394. https:// doi.org/10.3390/su12083394

Publisher's Note Springer Nature remains neutral with regard to jurisdictional claims in published maps and institutional affiliations. 